\title{
Trace determination of cadmium in water using anodic stripping voltammetry at a carbon paste electrode modified with coconut shell powder
}

\author{
Deepak Singh Rajawat ${ }^{1}$, Nitin Kumar ${ }^{2}$ and Soami Piara Satsangee ${ }^{3^{*}}$
}

\begin{abstract}
Background: Increasing awareness on the environmental impact of heavy metals has increased a considerable interest in the determination of metals in natural water bodies. The present paper describes the development and electrochemical application of carbon paste electrode modified with fibrous part of coconut shell for the determination of cadmium in water samples.

Methods: Determination was carried out using anodic stripping voltammetry. It is a two-step process. First, the metal ions get accumulated at the electrode surface at open-circuit potential, followed by a potential scan for voltammetric determination of cadmium.

Results: Different parameters affecting the determination of $\mathrm{Cd}(\mathrm{II})$ were optimized and are as follows: $\mathrm{HCl}$ as stripping solvent, acetate buffer of pH 5 as accumulating solvent, and 15-min accumulation time. Triton X-100, cetyltrimethylammonium bromide, and sodium dodecyl sulfate were used as representative for neutral, cationic, and anionic surfactants, respectively, to see the effect of surface active macromolecules. Interference caused by other metal ions on the determination of cadmium was also studied.
\end{abstract}

Conclusions: The method shows the development of a sensor for the sensitive determination of cadmium with limit of detection at $105 \mu \mathrm{g} \mathrm{L}{ }^{-1}$. This technique does not use mercury and, therefore, has a positive environmental benefit.

Keywords: Plant-modified carbon paste electrode; Cocos nucifera; Cadmium; Stripping voltammetry

\section{Background}

Cadmium is classified as one of the priority pollutants which entered water streams through various industrial operations (Pan et al. 2012). It is ranked seventh by the Environmental Protection Agency in 'Top hazardous substances priority list'. Cadmium can easily be dissolved and transported by water ( $\mathrm{Li}$ et al. 2009a, b). However, due to anthropogenic activities, its content can be elevated at the site of the action. High concentrations of cadmium ions can injure human health and pollute the environment. It is carcinogenic to human by damaging human immune and central nervous systems and causes diseases such as renal dysfunction and liver damage. Hence, the identification of cadmium-polluted sites is needed by society (Eshaghi et al. 2011).

Different analytical methods for the determination of Cd (II) ions have been reviewed several times (Sneddon

* Correspondence: electrochemanal@gmail.com

${ }^{3}$ Remote Instrumentation Lab, USIC, Dayalbagh Educational Institute, Agra 282010, India Full list of author information is available at the end of the article and Vincent 2008; Ferreira et al. 2007; Pyrzynska 2007; Davis et al. 2006). Among them is stripping voltammetric determination of cadmium using mercury-based electrodes which is one of the very sensitive analytical methods available. But, due to different issues related to its harmful effects and disposal, it is strongly recommended to replace mercury with another electrode material. Recently, modified carbon paste electrodes can be a better substitute of mercury-based electrodes due to its simplicity of preparation, the versatility of chemical modification, rapid renewal of the electrode surface, and sensitivity equivalent to that of mercury-based electrodes (Roa et al. 2003; Sar et al. 2008; Heitzmann et al. 2005; Lu et al. 2011; Li et al. 2009a, b; Bagheri et al. 2012). Thus, modified carbon paste electrodes (MCPEs) and related sensors using different types of modifiers (chemicals, enzymes, and extracts) have been developed (Chow and Gooding 2006; Heitzmann et al. 2005; Ensafi et al. 2010; Portaccio et al. 2010). 
In comparison to the conventionally used MCPEs, plantmodified carbon paste electrodes represent a green approach in the environmental perspectives. The use of plant agricultural wastes as a modifier in carbon paste electrodes is due to the high metal hyper-accumulating properties in certain plants (Rajawat et al. 2013b; Mojica et al. 2006, 2007). They possess an electrochemically or chemically active moiety. These moieties could be any of the following: redox or ligand sites and ion-exchange sites, which possess certain functionalities or donor groups (Rajawat and Satsangee 2011).

Coconut shell has been widely used as an agricultural waste material for the sorption of Cd (II) from aqueous solution (Pino et al. 2006; Okafor et al. 2012). In continuation of our previous research work on modified carbon paste electrodes (Rajawat et al. 2012, 2013a) and keeping the above views in mind, the powder of coconut shell (Cocos nucifera) was used to modify the carbon paste electrode with the main goal of using it as a modifier material for the development of a sensor for the determination of cadmium.

\section{Methods}

\section{Chemicals and reagents}

For DPASV study, first, accumulation was done under opencircuit potential by placing the electrode in a metal solution with stirring for a certain time, rinsed with deionized distilled water followed by medium exchange for stripping analysis.

All chemicals were of analytical reagent grade. A 1,000ppm stock solution of Cd (II) was prepared by dissolving an appropriate amount of cadmium nitrate (Merck \& Co., Inc., Whitehouse Station, NJ, USA). The working solution was prepared daily by the dilutions from the stock solution. Graphite powder $(<20 \mu \mathrm{m})$ and mineral oil Nujol (light, density 0.838) were obtained from Aldrich (Wyoming, IL, USA). Triply distilled water (ELGA, Millipore Co., Billerica, MA, USA) was used throughout the experiment.

\section{Procedure}

All quantitative measurements were carried out in anodic stripping voltammetry using differential pulse (DP) to achieve the sensitivity required for trace analysis. Each DPASV run was made up of two steps: accumulation under open circuit where the modified electrode is immersed in metal solution for a certain time. The electrode was then rinsed with deionized distilled water, followed by medium ex-change for stripping analysis. All measurements were carried out at room temperature $\left(24 \pm 1^{\circ} \mathrm{C}\right)$. Finally, the calibration curves were plotted and the influence of various substances as potential interference compounds on the determination of $\mathrm{Cd}(\mathrm{II})$ ions was studied under the optimum conditions.

\section{Preparation of coconut shell powder-modified carbon paste electrode}

Coconut was purchased from the local market of Agra. The coconut shell between the outer layer and inner layer (i.e., mesocarp) was separated. It was properly washed with water and dried in an oven at $50^{\circ} \mathrm{C}$. The dried material was grounded and passed through the sieve. Fraction of the particles with size less than $150 \mu \mathrm{m}$ was selected for electrode preparation. Unmodified carbon paste electrode was prepared by mixing the graphite powder with the mineral oil (80:20 $w / w$ ratio) using mortar and pestle. MCPEs of different proportions $(5 \%, 10 \%, 15 \%, 20 \%, 25 \%$, and $30 \% \mathrm{w} / w$ ) were prepared by substituting the corresponding amount of graphite powder with coconut shell powder. The mixture is thoroughly hand-mixed in a mortar and pestle. The paste was pressed in a glass tube with an inner diameter of $3 \mathrm{~mm}$ and a depth of $4 \mathrm{~cm}$ to form a target electrode surface. A copper wire was inserted from the backside for electrical contact. A smooth and fresh electrode surface was obtained by pushing the electrode material from the backside, removing a small amount of paste from the electrode tip, and polishing the electrode surface on a photo paper.

\section{Results and discussion}

\section{Characterization of the coconut shell powder-modified carbon paste electrode Morphological characterization}

Scanning electron microscope images of (a) unmodified and (b) coconut shell powder-modified carbon paste electrodes are shown in Figure 1. The comparison of the scanning electron microscope (SEM) images shows a difference in the morphology which was observed after the modification with coconut shell powder. The unmodified CPE surface is homogenous and fine pores are uniformly distributed, whereas after the modification, the pore size was increased and the distribution of the pores on the surface become uneven.

Increase in the roughness value for coconut shell powdermodified CPE (CS-MCPE) was justified with the atomic force microscope (AFM) results. 3-D atomic force microscope images of unmodified CPE (a) and CS-MCPE (b) are shown in Figure 2. Increase in the average surface roughness of the prepared electrode was observed after modification with coconut shell powder from 84.55 to $183.96 \mathrm{~nm}$, respectively, for unmodified and modified CPE. It justifies the results obtained from SEM.

\section{Electrochemical characterization}

All the electrochemical experiments were performed using a $\mu$ Autolab Type III potentiostat (Eco Chemie, Utrecht, Netherlands) controlled by a PC using the NOVA 1.8 software. A three-electrode system containing the modified carbon paste electrode as working, an $\mathrm{Ag} / \mathrm{AgCl}$ (3.0 $\left.\mathrm{mol} \mathrm{L}^{-1} \mathrm{KCl}\right)$ as reference, and a platinum wire as auxiliary electrodes was used.

Electrochemical characterization of the prepared electrodes was carried out using cyclic voltammetry. Cyclic voltammetry study for the CS-MCPE in $\mathrm{K}_{3}\left[\mathrm{Fe}(\mathrm{CN})_{6}\right]$ solution with $0.1 \mathrm{M} \mathrm{KCl}$ as supporting electrolyte was 


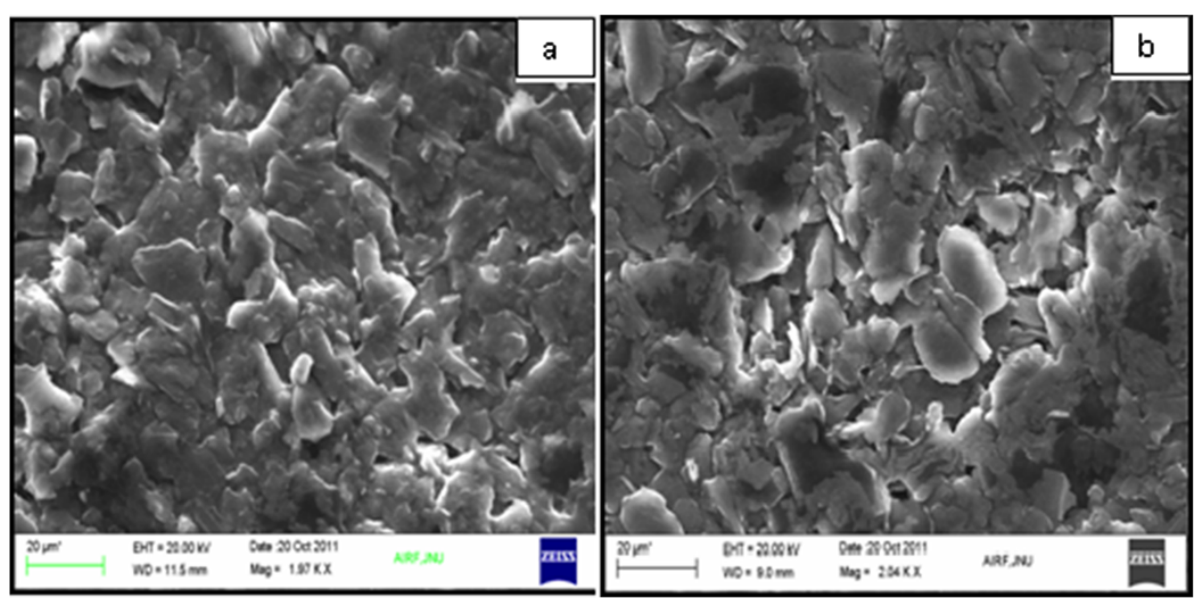

Figure 1 SEM images of the carbon paste electrode. (a) Unmodified carbon paste electrode and (b) coconut shell powder-modified carbon paste electrode.

carried out to determine the effect of modification on charge transfer activity, and the results are given in Figure 3. Well-defined cyclic voltammogram (CV) was observed for the unmodified CPE (Figure 3, curve a). With modified CPE, the redox peak currents decreased, and the peak potential difference increased remarkably (Figure 3, curve b). Because the coconut shell powder acts as an inert electron and a mass transfer blocking layer, it hinders the diffusion of ferricyanide toward the electrode surface. Based on the $\mathrm{CV}$ results, we can conclude that the coconut shell powder was successfully embedded on the surface of the modified electrode.

\section{Electrochemical impedance study}

The FRA module with the same instrumental setup was used for the electrochemical impedance study (EIS). For EIS, the AC amplitude of $10 \mathrm{mV}$ at a frequency of 1 to $100,000 \mathrm{~Hz}$ was applied. Figure 4 shows the Nyquist plots of the electrochemical impedance study for the unmodified (Figure 4 curve a) and modified (Figure 4 curve b) CPE in
$10 \mathrm{mM} \mathrm{K}_{3}\left[\mathrm{Fe}(\mathrm{CN})_{6}\right]$ solution. The results of the EIS studies were analyzed by fitting the appropriate equivalent circuit. The circuit which most fitted to the unmodified CPE is given in Figure $4 \mathrm{~b}$. Here, $R_{\mathrm{s}}$ is the solution resistance, $Q$ is a constant phase element, and $R_{\mathrm{p}}$ is charge transfer resistance. The same circuit was used to analyze the EIS results of the CS-MCPE. The charge transfer resistance value observed for CS-MCPE is high in comparison to the unmodified CPE. The electrochemical impedance spectroscopy results are in accordance with the cyclic voltammetry results.

\section{Electrochemical studies for metal determination}

The ability of the CS-MCPE for the determination of Cd (II) was evaluated by the accumulation of Cd (II) at opencircuit potential and its electrochemical stripping in electrolyte solution using cyclic voltammetry. The CV curves recorded in $0.1 \mathrm{M}$ hydrochloric acid did not show any peak without accumulation (Figure 5 curve a), whereas after accumulation for $10 \mathrm{~min}$, well-defined oxidation peak appears (Figure 5 curve b), corresponding to the
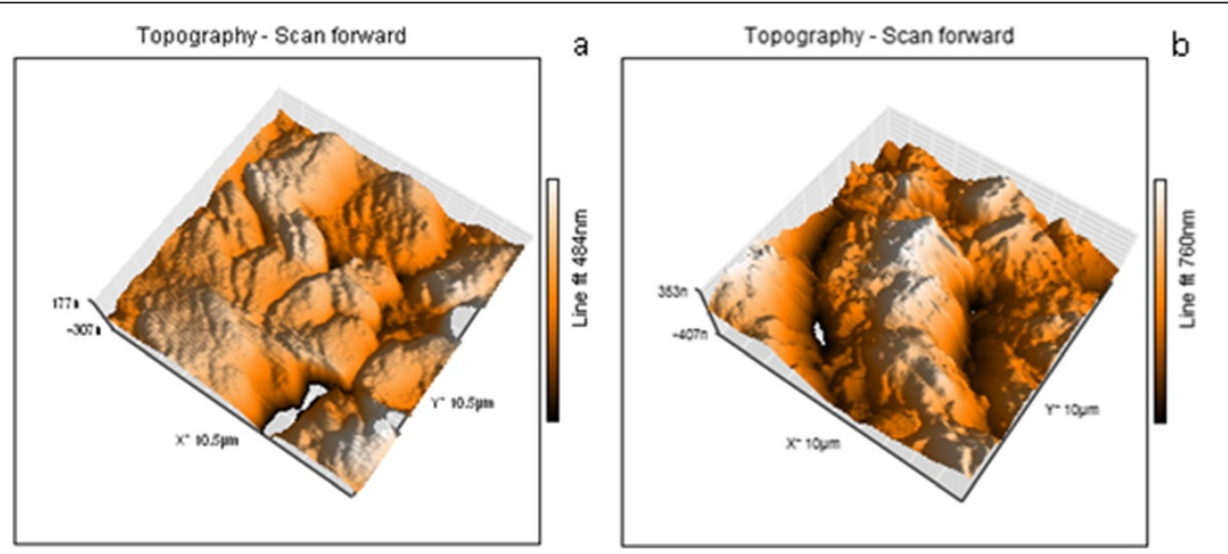

Figure 2 AFM images of the carbon paste electrode. (a) Unmodified carbon paste electrode and (b) coconut shell powder-modified carbon paste electrode. 


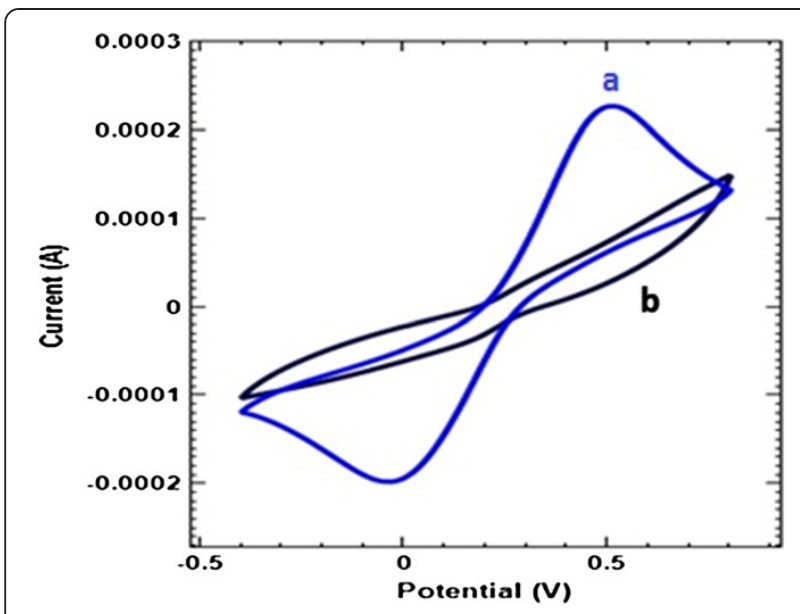

Figure 3 Cyclic voltammograms of the carbon paste electrode. (a) Unmodified CPE and (b) coconut shell powder-modified carbon paste electrode in potassium ferricyanide solution with $0.1 \mathrm{M} \mathrm{KCl}$ at the scan rate of $100 \mathrm{mV} / \mathrm{s}$.

oxidation of the accumulated cadmium which proves that cadmium metal gets accumulated at the electrode surface.

Based on the cyclic voltammetric results, differential pulse anodic stripping voltammetry (DPASV) was used. The DPASV result show a well-defined and symmetric anodic stripping peak with peak potential at $-713 \mathrm{mV}$ after the accumulation (Figure 6 curve b), whereas a flat curve was attained without accumulation (Figure 6 curve a). So, the peak was because of the oxidation of $\mathrm{Cd}$ (II) in the stripping step. Therefore, differential pulse anodic stripping

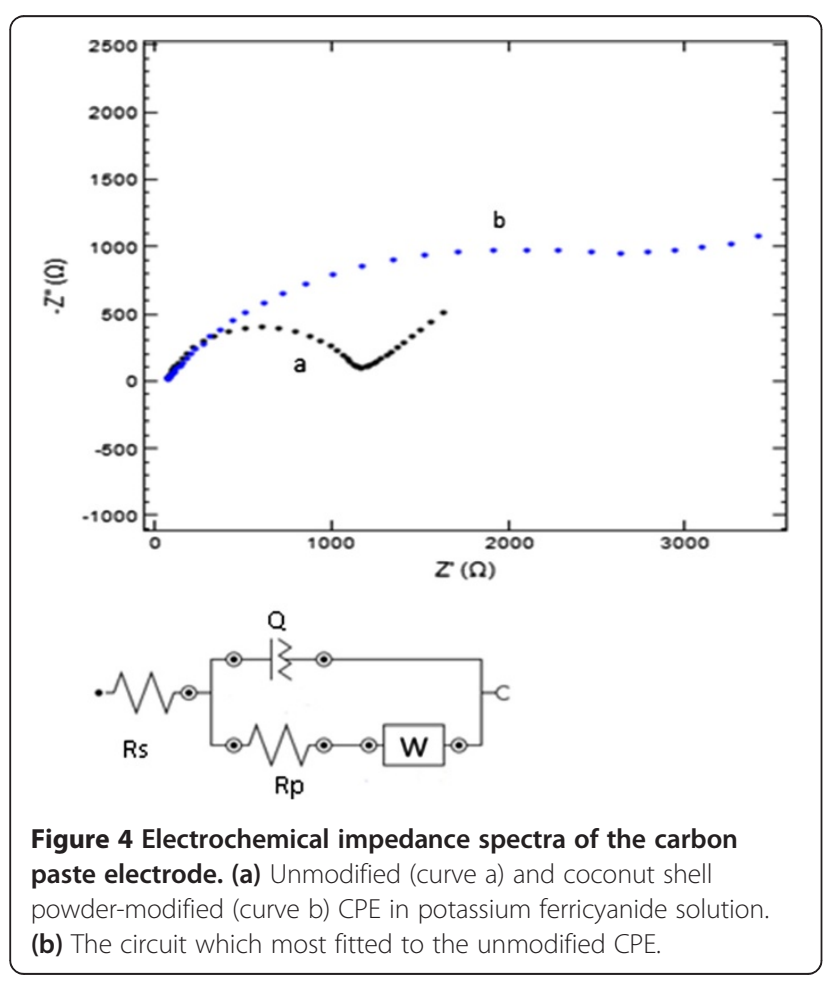

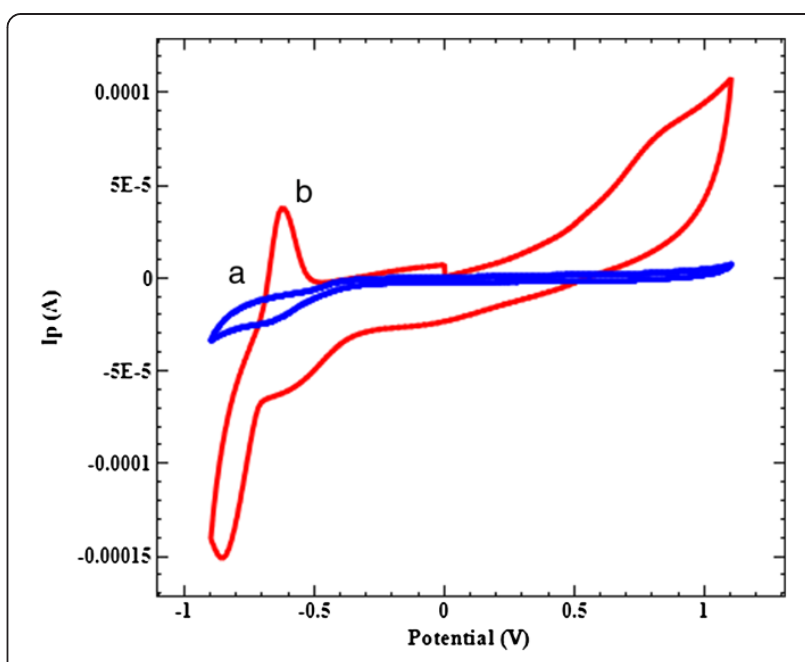

Figure 5 Cyclic voltammograms of coconut shell powder-modified carbon paste electrode in $0.1 \mathrm{M} \mathrm{HCl}$. (a) Without accumulation and (b) after 10-min accumulation of Cd (II) at a scan rate of $50 \mathrm{mV} / \mathrm{s}$.

voltammetry was employed in the present work for the determination of cadmium. All measurements were carried out at room temperature $\left(24^{\circ} \mathrm{C} \pm 1^{\circ} \mathrm{C}\right)$. During the experiment, the electrodes were stored in $0.1 \mathrm{M} \mathrm{HCl}$ solution.

\section{FTIR studies}

The accumulation of metals at the electrode surface is thought to be mainly by electrostatic attraction between different functional groups on the coconut shell powder embedded at the electrode surface and cationic metal ions. Ionization of these groups in aqueous solution enables them to participate in cation binding. The binding of the metal ions at the electrode surface was studied using FTIR. An FTIR spectrum of the coconut shell powder before and after its treatment with metal solution

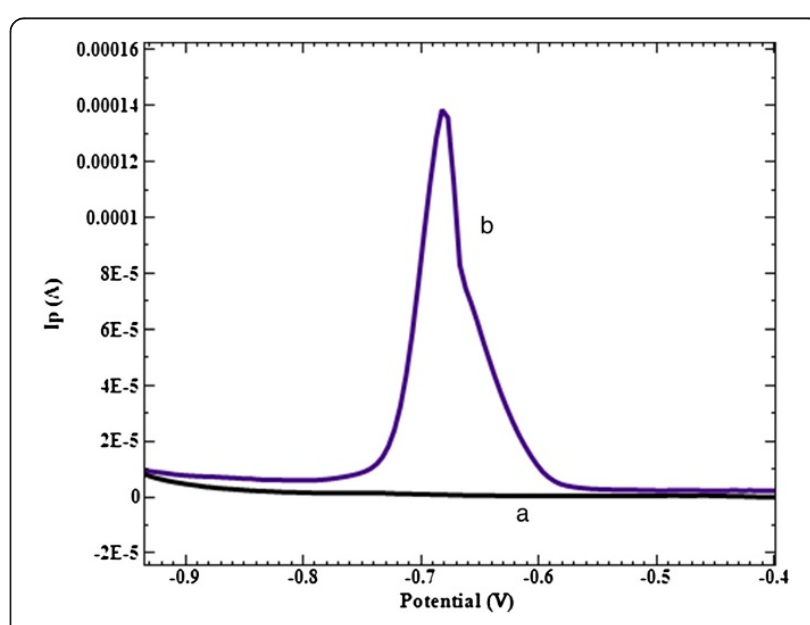

Figure 6 Differential pulse anodic stripping voltammograms for determination of Cd (II). (a) Before accumulation and (b) after 10-min accumulation; stripping solution is $0.1 \mathrm{M} \mathrm{HCl}$. 
is shown in Figure 7. The FTIR spectroscope analysis of the finely powdered and dried coconut shell powder (native) indicates broad absorption bands at 3,425.5, 1,625.9, 1,448.5, and $1,261.4 \mathrm{~cm}^{-1}$ (Figure 7 spectrum a) representing $-\mathrm{OH}$ stretching, $\mathrm{C}=\mathrm{O}$ stretching, $\mathrm{OH}$ bending, and $\mathrm{C}-\mathrm{O}$ stretching vibrations. After treatment with $\mathrm{Cd}$ (II), the adsorption bands shifted to $3,431.3,1,631.7,1,446.6$, and $1,257.7 \mathrm{~cm}^{-1}$, respectively (Figure 7 spectrum b). Slight shift in the adsorption bands indicated that the $-\mathrm{OH}, \mathrm{C}-\mathrm{O}$, and $\mathrm{C}=\mathrm{O}$ groups are involved in the $\mathrm{Cd}$ (II) binding.

\section{Mechanism of accumulation}

Based on our experimental findings and pertinent information available on the relevant topic, a mechanism for metal binding at the modified electrode surface is proposed. Coconut shell powder contains oxygen-containing functional groups in lignins and cellulose. These groups may constitute a physiologically active group to interact with the $\mathrm{Cd}$ (II) ions. The mechanism of the accumulation at the modified electrode is as follows:

\section{Optimization parameters}

Different parameters affecting the voltammetric determination of Cd (II) such as amount of modifier, accumulation media, accumulation time, and stripping media were investigated.

\section{Amount of modifier}

The effect of the amount of coconut shell powder in the modified CPE on the peak current was investigated and shown in Figure 8. The results indicated that the peak current increases with the increase in the amount of coconut shell powder initially because the increase in the amount of the coconut shell powder results in the increase of binding sites, which facilitates the accumulation of cadmium at the electrode surface. However, at $20 \%$ of coconut shell powder relative to the mass of carbon powder, the highest peak currents were obtained. After $20 \%$ modifier, the continuous increase in the amount of the modifier causes a decrease of the peak current, because excessive coconut shell powder results in the decrease of conductivity of the modified electrode.
$\left(\mathrm{Cd}^{2+}\right)_{\text {solution }}+(\mathrm{MCPE})$ surface
$\left(\mathrm{Cd}^{2+}-\mathrm{MCPE}\right)_{\mathrm{adsorb}}$
(Accumulation step)
$\left.\left(\mathrm{Cd}^{2+}-\mathrm{MCPE}\right)\right)_{\mathrm{adsorb}}+\mathrm{ne}-$
$\left(\mathrm{Cd}^{0}, \mathrm{MCPE}\right)$ adsorb
(Reduction step)
$\left(\mathrm{Cd}^{0}-\mathrm{MCPE}\right)_{\mathrm{adsorb}^{-}}$ne -
$\left(\mathrm{Cd}^{2+}\right)_{\text {solution }}+(\mathrm{MCPE})_{\text {surface }}$
(Stripping step)

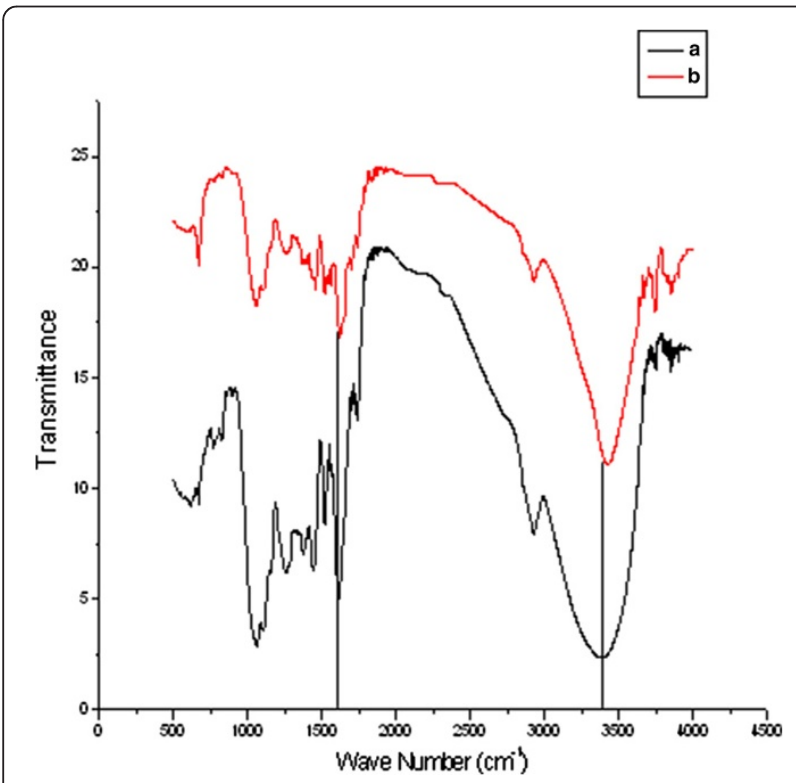

Figure 7 FTIR spectra of coconut shell powder before (a) and after treatment with Cd (II) (b).

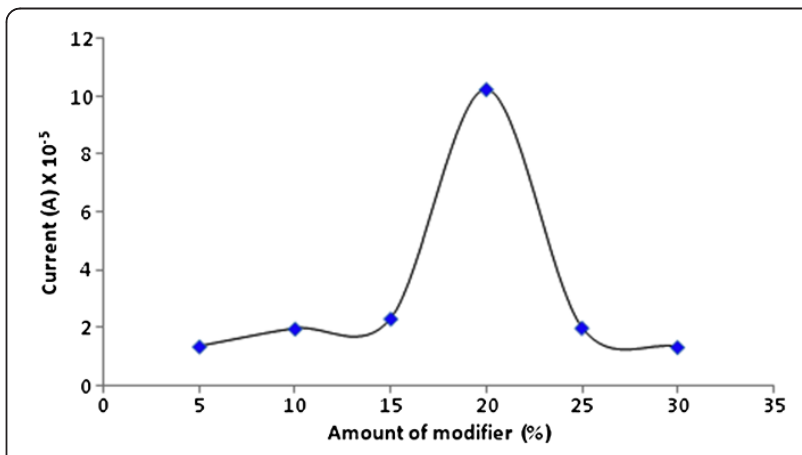

Figure 8 Effect of the amount of modifier on DPASV current response. 
So, the best ratio of the modifier in the carbon paste composition is $20 \%(w / w)$ for the determination of Cd (II).

\section{Accumulation media}

The accumulation of cadmium was examined in supporting electrolytes such as acid solution, base solution, and different buffers like acetate buffer, phosphate buffer, and Britton-Robinson buffer. Voltammetric peaks were observed in most of these electrolytes; however, in acetate buffer solution, the anodic peak current was higher, and better defined peak shape was observed for Cd (II). A baseline for the determination of metals in acetate buffer is comparatively low, suggesting acetate buffer as the best accumulating medium.

The effect of the $\mathrm{pH}$ of accumulating media on the voltammetric response of the CS-MCPE was studied in a $\mathrm{pH}$ range between 3.0 to 6.0 in a solution containing $1 \mathrm{ppm}$ Cd (II) with $1 \mathrm{mM}$ sodium acetate buffer. As shown in Figure 9, anodic peaks current was increased as the $\mathrm{pH}$ is changed from 3.0 to 6.0 , reaching a maximum at $\mathrm{pH} 5$ and then decreases. The results show that maximum binding of these metal ions on the electrode surface occurs at $\mathrm{pH} 5$. Since the ionization of functional groups depends on the accumulating solvents and its $\mathrm{pH}$, at $\mathrm{pH}>\mathrm{pKa}$, most of these functional groups are mainly in ionized form and can exchange $\mathrm{H}^{+}$with metal ions in a solution. The concentration of acetate buffer was also varied from 0.1 to $100 \mathrm{mM}$. The maximum current value was obtained for $1 \mathrm{mM}$ acetate buffer.

\section{Accumulation time}

The influence of accumulation time on the stripping peak currents of $0.1,1$, and $10 \mathrm{ppm}$ of $\mathrm{Cd}$ (II) in $1 \mathrm{mM}$ sodium acetate buffer solution was investigated. An increase in the current response was observed with increasing preconcentration time initially, which indicates that cadmium was rapidly adsorbed on the modified electrode surface while further prolonged accumulation did not improve the peak height. In comparison to the three concentrations of

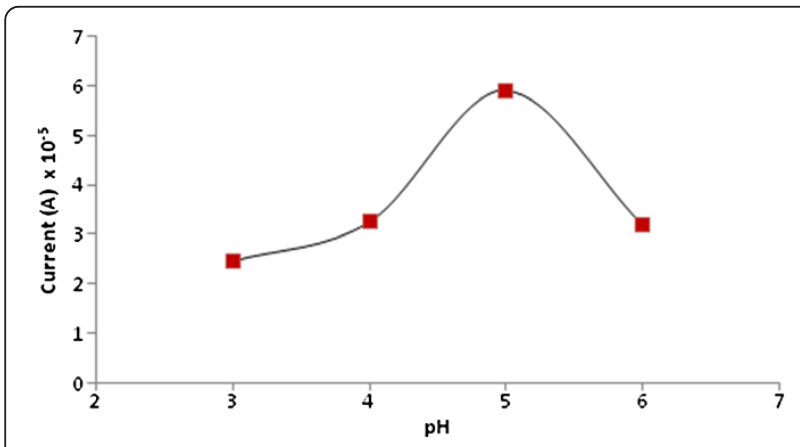

Figure 9 Effect of $\mathrm{pH}$ of accumulating solvent on the DPASV response of the modified carbon paste electrode. metal ions selected for this experiment, the electrode surface gets saturated early for higher concentration compared to the low concentration. For further experiment, 1 ppm Cd (II) solution was used with accumulation time of $10 \mathrm{~min}$.

\section{Stripping media}

The influence of the nature of stripping medium on the current response was investigated using hydrochloric acid, nitric acid, sulfuric acid, perchloric acid, phosphoric acid, sodium hydroxide, ammonium hydroxide, sodium chloride, and potassium chloride; the results are shown in Figure 10. The maximum current response was observed for hydrochloric acid solution as a stripping media, since in acidic solutions, its protons have the ability to displace the $\mathrm{Cd}$ (II) ions; in addition, the chloride ions of $\mathrm{HCl}$ promotes the stripping of metals. It is evident from the previous studies that the $\mathrm{Cl}^{-}$ion is the best migrating ligand for Cd (II) (Rajawat et al. 2013a). The effect of the stripping solvent concentration was also studied by varying the concentration within the range 0.01 to $1 \mathrm{M}$. The optimum current response was observed at $0.1 \mathrm{M} \mathrm{HCl}$.

\section{Determination of metals in the presence of surfactants}

The effect of the presence of the surfactants on the determination of Cd (II) was carried out using Triton X100, SDS, and CTAB as representatives of non-ionic, anionic, and cationic surfactants, respectively. Typical voltammograms in the presence of increasing amounts of each surfactant were recorded, and the effect of surfactant on current value was presented in Figure 11. An increase in the current response was observed for the anionic surfactants, whereas for the cationic

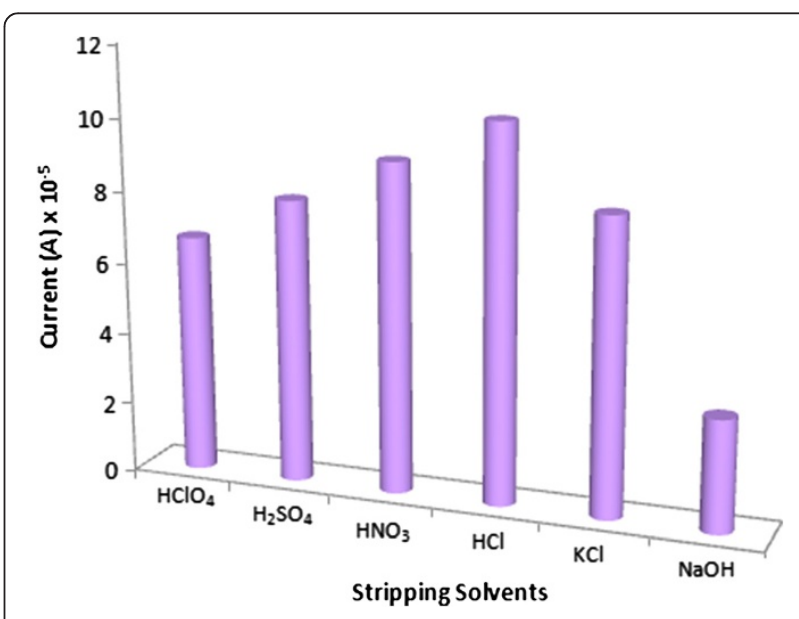

Figure 10 Effect of different stripping solvents on DPASV current response. 


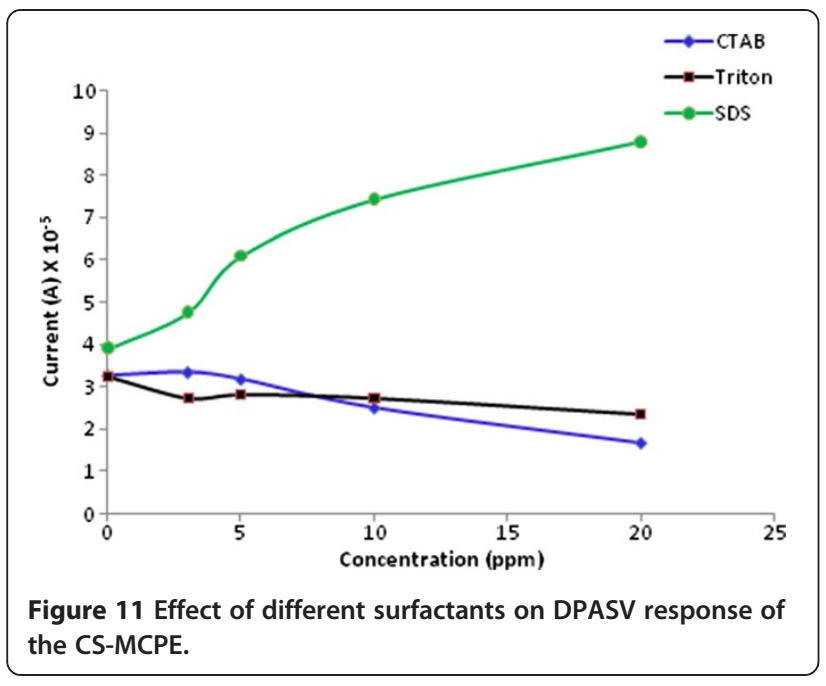

surfactants, a decrease in the current response was observed. For neutral surfactant, not so much change was observed. No variation in the peak potential value was observed for Cd (II) determination on increasing amount of surfactant.

\section{Interference study}

The effect of the presence of other metal ions present in the solution on the anodic peak currents of Cd (II) was evaluated. A $10 \%$ change in the current response is assumed as a constant current response. No effect on the determination of $\mathrm{Cd}$ (II) was observed up to 250-fold of $\mathrm{Pb}$ (II), 5-fold of $\mathrm{Cu}$ (II), 25-fold Ni (II), and 30-fold $\mathrm{Cr}$ (VI). The results of interference study can be justified by hard-soft acid base theory. The main binding sites in these modifiers are $\mathrm{COOH}$ and $\mathrm{OH}$ groups, which are hard bases, whereas the metals $\mathrm{Pb}$ (II) and $\mathrm{Cu}$ (II) are intermediate; $\mathrm{Cd}$ (II), $\mathrm{Hg}$ (I), and $\mathrm{Zn}$ (II) are soft acids. According to hard-soft acid base theory, hard acid tends to form complexes with hard bases, and soft acids tend to form complexes with soft bases. Since copper is strongly bonded on electrode surface, so it is the most interfering metal.

\section{Analytical characteristics}

Analytical performance of the CS-MCPE was evaluated with standard addition of $\mathrm{Cd}$ (II) under the optimum conditions determined above, and the corresponding results are shown in Figure 12. A linear relationship was observed between the analytical signal and concentration ranging from 200 to $650 \mu \mathrm{gL}^{-1}$. In this region, the resulting equation is $y=31.21 x-1.154$, with a correlation coefficient 0.998 .

The detection limit is evaluated to be about $105 \mathrm{ppb}$ $(S / N=3)$ after a 15 -min accumulation. The limit of detection of the prepared electrodes was compared with

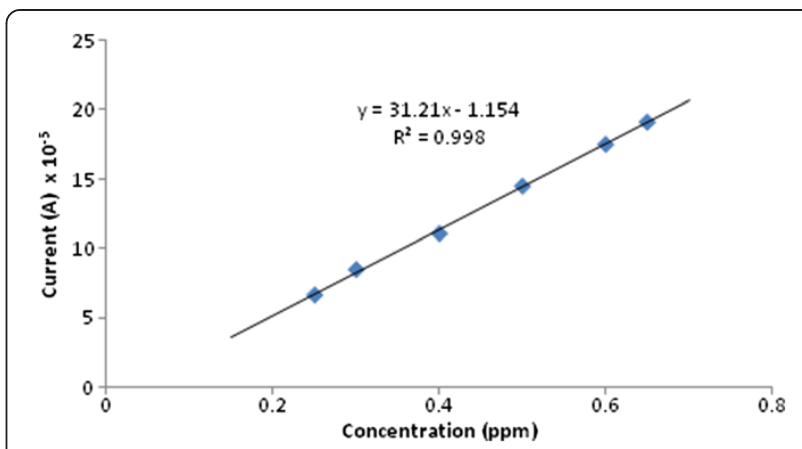

Figure 12 Standard addition curve for the determination of $\mathrm{Cd}(\mathrm{II})$ under the optimized conditions for $15 \mathrm{~min}$ preconcentration time.

the previously prepared electrodes; it is comparatively better with some of the previously reported electrodes (Beltagi et al. 2011; Roa et al. 2003). The stability of the prepared electrode was determined using the DPASV for the same modified electrode with an interval of 2 weeks over 6 months, and it was found 6 months, assuming 5\% change in the current response as a constant current response.

\section{Conclusion}

The present paper demonstrates a simple, ecofriendly, and sensitive electrochemical method for the determination of cadmium based on the coconut shell powdermodified carbon paste electrode. Cyclic voltammetry and electrochemical impedance spectroscopy study results confirm the incorporation of coconut shell powder at the electrode surface. Open-circuit accumulation, followed by anodic stripping voltammetry, was used for the determination of cadmium. An enhancement in the current response was observed in the presence of anionic surfactants. Different factors affecting the sensitivity of the prepared electrode were optimized. The optimized conditions for the determination of Cd (II) using CSMCPE are acetate buffer of $\mathrm{pH}=5$ as accumulating solvent, $15 \mathrm{~min}$ accumulation time and hydrochloric acid as the stripping solvent. Despite some mutual interference effects, cadmium ions can be reliably determined with low detection limits using the standard addition procedure. The utilization of plant-based electrode in place of mercury-based electrodes is an attempt to perform environment friendly electrochemical determination of cadmium.

\section{Abbreviations}

CPE: carbon paste electrode; CS-MCPE: coconut shell powder-modified carbon paste electrode; CTAB: cetyltrimethylammonium bromide; CV: cyclic

voltammogram; DPASV: differential pulse anodic stripping voltammetry; FTIR: Fourier transform infrared; MCPE: modified carbon paste electrode; SDS: sodium dodecyl sulfate; SEM: scanning electron microscope. 


\section{Competing interests}

The authors gratefully acknowledge Prof. V.G. Dass, Director, Dayalbagh Educational Institute, Dayalbagh, Agra, for providing necessary research facilities. The authors also thank Ministry of Human Resource and Development, New Delhi for rendering financial assistance.

\section{Author details}

${ }^{1}$ Department of Chemistry, IIS University, Jaipur 302020, India. ${ }^{2}$ Department of Chemistry, MLS University, Udaipur 313001, India. ${ }^{3}$ Remote Instrumentation Lab, USIC, Dayalbagh Educational Institute, Agra 282010, India.

Received: 17 March 2013 Accepted: 8 January 2014

Published online: 08 May 2014

\section{References}

Bagheri H, Afkhami A, Shirzadmehr A, Khoshsafar H, Ghaedi H (2012) Novel potentiometric sensor for the determination of $\mathrm{Cd}^{2+}$ based on a new nano-composite. Int J Environ Anal Chem, doi:10.1080/03067 319.2011.649741

Beltagi AM, Ghoneim EM, Ghoneim MM (2011) Simultaneous determination of cadmium (II), lead (II), copper (II) and mercury (II) by square wave anodic stripping voltammetry at a montmorillonite calcium modified carbon paste electrode. Int J Environ Anal Chem 91(1):17-32

Chow E, Gooding JJ (2006) Peptide modified electrodes as electrochemical metal Ion sensors. Electroanal 18:1437-1448

Davis AC, Wu P, Zhang XF, Hou XD, Jones BT (2006) Determination of cadmium in biological samples. Appl Spectrosc Rev 41:35-75

Ensafi AA, Arabzadeh A, Karimi-Maleh H (2010) Simultaneous determination of dopamine and uric acid by electrocatalytic oxidation on a carbon paste electrode using pyrogallol red as a mediator. Anal Lett 43:1976-1988

Eshaghi Z, Khalili M, Khazaeifar A, Rounaghi GH (2011) Simultaneous extraction and determination of lead, cadmium and copper in rice samples by a new pre-concentration technique: hollow fiber solid phase microextraction combined with differential pulse anodic stripping voltammetry. Electrochim Acta 56:3139-3146

Ferreira SLC, Andrade JBD, Korn MDA, Pereira MD, Lemos VA, Dos Santos WNL, Rodrigues FD, Souza AS, Ferreira HS, Da Silva EGP (2007) Review of procedures involving separation and preconcentration for the determination of cadmium using spectrometric techniques. J Hazard Mater 145:358-367

Heitzmann M, Basaez L, Brovelli F, Bucher C, Limosin D, Pereira E, Rivas BL, Royal G, Aman ES, Moutet JC (2005) Voltammetric sensing of trace metals at a poly (pyrrole-malonic acid) film modified carbon electrode. Electroanal 17:1970-1976

Li J, Guo S, Zhai Y, Wang E (2009a) Nafion-graphene nanocomposite film as an enhanced sensing platform for ultrasensitive determination of cadmium. Electrochem Commun 11:1085-1088

Li Y, Liu X, Zeng X, Liu Y, Liu X, Wei W, Luo S (2009b) Simultaneous determination of ultra-trace lead and cadmium at a hydroxyl apatite-modified carbon ionic liquid electrode by square-wave stripping voltammetry. Sensor Actuat B-Chemical 139:604-610

Lu M, Toghill KE, Compton RG (2011) Simultaneous detection of trace cadmium (II) and lead (II) using an unmodified edge plane pyrolytic graphite electrode. Electroanal 23:1089-1094

Mojica ERE, Micor JRL, Gomez SP, Deocaris CC (2006) Lead detection using a pineapple bioelectrode. Philipp Agric Sci 89:134-140

Mojica ERE, Vidal JM, Pelegrina AB, Micor JRL (2007) Voltammetric determination of lead (ii) ions at carbon paste electrode modified with banana tissue. J Appl Sci 7:1286-1292

Okafor PC, Okon PU, Daniel EF, Ebenso EE (2012) Adsorption capacity of coconut (Cocos nucifera L.) shell for lead, copper, cadmium and arsenic from aqueous solutions. Int J Electrochem Sci 7:12354-12369

Pan D, Zhang L, Zhuang J, Lu W, Zhu R, Qin W (2012) New application of tin-bismuth alloy for electrochemical determination of cadmium. Mater Lett 68:472-474

Pino GH, Mesquita LMS, Torem ML, Pinto GAS (2006) Biosorption of cadmium by green coconut shell powder. Min Eng 19:380-387

Portaccio M, Tuoro DD, Arduini F, Lepore M, Mita DG, Diano N, Mita L, Moscone D (2010) A thionine-modified carbon paste amperometric biosensor for catechol and bisphenol A determination. Biosens Bioelectron 25:2003-2008

Pyrzynska K (2007) Online sample pretreatment systems for determination of cadmium by the ETAAS method. Crit Rev Anal Chem 37:39-49
Rajawat DS, Satsangee SP (2011) Voltammetric determination of Pb (II) ions by carbon paste electrode modified with lemon grass powder. Res J Chem Environ 15:55-60

Rajawat DS, Srivastava S, Satsangee SP (2012) Electro Chemical Determination of $\mathrm{Pb}$ (II) lons by Carbon Paste Electrode Modified with Coconut Powder. In: Chemistry of Phytopotentials: Health, Energy and Environmental Perspectives, Springer, Berlin Heidelberg, pp 293-297

Rajawat DS, Kardam A, Srivastava S, Satsangee SP (2013a) Nano cellulosic fibers modified carbon paste electrode for ultra trace determination of $\mathrm{Cd}$ (II) and $\mathrm{Pb}$ (II) in aqueous solution. Environ Sci Pollut Res Environ Sci Pollut Res 20:3068-3076

Rajawat DS, Kardam A, Srivastava S, Satsangee SP (2013b) Adsorptive stripping voltammetric technique for monitoring of mercury ions in aqueous solution using nano cellulosic fibers modified carbon paste electrode. Nat Aca Sci Lett 36:181-189

Roa G, Ramírez-Silva MT, Romero-Romo MA, Galicia L (2003) Determination of lead and cadmium using a polycyclodextrin-modified carbon paste electrode with anodic stripping voltammetry. Anal Bioanal Chem 377:763-769

Sar E, Berber H, Asc B, Cankurtaran H (2008) Determination of some heavy metal ions with a carbon paste electrode modified by poly (glycidylmethacrylate-methylmethacrylate-divinylbenzene) microspheres functionalized by 2-aminothiazole. Electroanal 20:1533-1541

Sneddon J, Vincent MD (2008) ICP-OES and ICP-MS for the determination of metals: application to oysters. Anal Lett 41:1291-1303

\section{doi:10.1186/s40543-014-0019-0}

Cite this article as: Rajawat et al:: Trace determination of cadmium in water using anodic stripping voltammetry at a carbon paste electrode modified with coconut shell powder. Journal of Analytical Science and Technology 2014 5:19.

\section{Submit your manuscript to a SpringerOpen ${ }^{\circ}$ journal and benefit from:}

- Convenient online submission

Rigorous peer review

- Immediate publication on acceptance

- Open access: articles freely available online

- High visibility within the field

- Retaining the copyright to your article

Submit your next manuscript at $>$ springeropen.com 